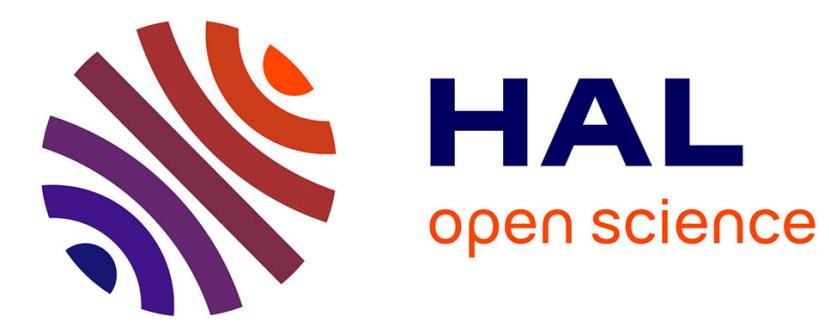

\title{
Thermal effect of plastic dissipation at the crack tip on the stress intensity factor under cyclic loading Nicolas Ranc, Thierry Palin-Luc, Paul Paris
}

\section{To cite this version:}

Nicolas Ranc, Thierry Palin-Luc, Paul Paris. Thermal effect of plastic dissipation at the crack tip on the stress intensity factor under cyclic loading. Engineering Fracture Mechanics, 2011, 78 (6), pp.961-972. 10.1016/j.engfracmech.2010.11.010 . hal-01057941

\section{HAL Id: hal-01057941 \\ https://hal.science/hal-01057941}

Submitted on 25 Aug 2014

HAL is a multi-disciplinary open access archive for the deposit and dissemination of scientific research documents, whether they are published or not. The documents may come from teaching and research institutions in France or abroad, or from public or private research centers.
L'archive ouverte pluridisciplinaire HAL, est destinée au dépôt et à la diffusion de documents scientifiques de niveau recherche, publiés ou non, émanant des établissements d'enseignement et de recherche français ou étrangers, des laboratoires publics ou privés. 


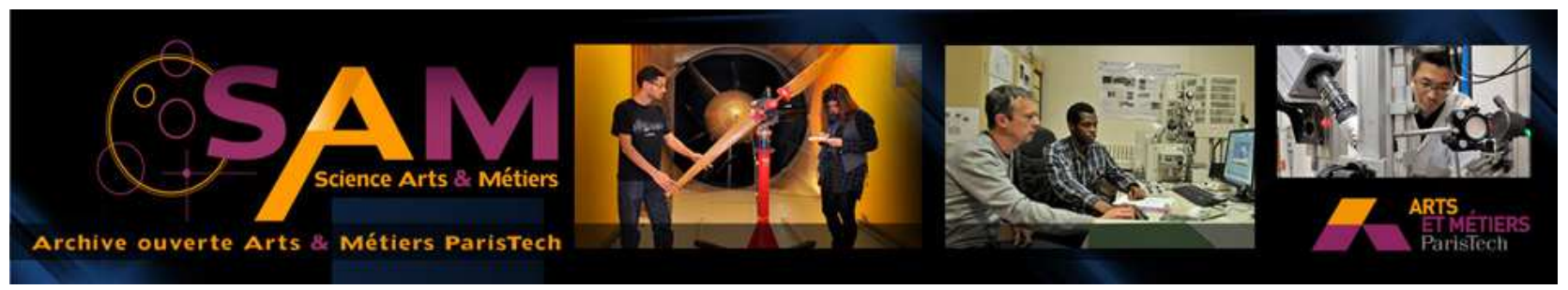

\section{Science Arts \& Métiers (SAM)}

is an open access repository that collects the work of Arts et Métiers ParisTech researchers and makes it freely available over the web where possible.

This is an author-deposited version published in: http://sam.ensam.eu

Handle ID: .http://hdl.handle.net/10985/8396

\section{To cite this version :}

Nicolas RANC, Thierry PALIN-LUC, Paul PARIS - Thermal effect of plastic dissipation at the crack tip on the stress intensity factor under cyclic loading - Engineering Fracture Mechanics - Vol. 78, $n^{\circ} 6, p .961-972-2011$ 


\title{
Thermal effect of plastic dissipation at the crack tip on the stress intensity factor under cyclic loading
}

\author{
N. Ranc ${ }^{a, *}$, T. Palin-Luc ${ }^{b}$, P.C. Paris ${ }^{b}$ \\ ${ }^{a}$ Arts et Métiers ParisTech, PIMM, UMR CNRS 8006, 151 Boulevard de l'Hôpital, F-75013 Paris, France \\ ${ }^{\mathrm{b}}$ Arts et Métiers ParisTech, Université Bordeaux 1, LAMEFIP, Esplanade des Arts et Métiers, F-33405 Talence Cedex, France
}

\section{Keywords:}

Stress intensity factor

Plastic dissipation

Reverse cyclic plastic zone

Thermal stress

\begin{abstract}
A B S T R A C T
Plastic dissipation at the crack tip under cyclic loading is responsible for the creation of an heterogeneous temperature field around the crack tip. A thermomechanical model is proposed in this paper for the theoretical problem of an infinite plate with a semi-infinite through crack under mode I cyclic loading both in plane stress or in plane strain condition. It is assumed that the heat source is located in the reverse cyclic plastic zone. The proposed analytical solution of the thermo-mechanical problem shows that the crack tip is under compression due to thermal stresses coming from the heterogeneous stress field around the crack tip. The effect of this stress field on the stress intensity factor (its maximum and its range) is calculated analytically for the infinite plate and by finite element analysis. The heat flux within the reverse cyclic plastic zone is the key parameter to quantify the effect of dissipation at the crack tip on the stress intensity factor.
\end{abstract}

\section{Introduction}

During a cyclic loading of a crack, the plasticity is located in the reverse cyclic plastic zone near the crack tip which was first explained by Paris [1] and studied later by Rice [2]. This effect is now well known and participates for instance in the explanation of the crack closure phenomenon which was first identified by Elber [3]. In metals, during plastic strain, a significant part of the plastic energy (around 90\% [4,5]) is converted in heat. The dissipated energy in the reverse cyclic plastic zone also generates a heterogeneous temperature field which depends on the intensity of the heat source associated with the plasticity and the thermal boundary conditions of the cracked structure. Due to the thermal expansion of the material, the temperature gradient near the crack tip creates thermal stresses which contribute to stress field associated with the cyclic loading of the crack. This thermal effect can also modify the stress intensity factor and the crack propagation.

The thermal effect due to the plasticity has been already studied in the case of a stationary and a running crack. Analytical [6,7], experimental [8-11] and numerical [12,7] methods allowed estimation of the temperature variation field near the crack tip and these studies show that this increase in the temperature can change the fracture mechanisms under monotonic loading.

In the case of the cyclic loading, some authors have used the infrared pyrometry technique in order to measure temperature field, quantify heat sources and study the materials properties [13-21]. Therefore these different studies have been carried out generally before crack initiation and no quantification of the temperature or the plastic work associated to the crack are given. However, in order to establish a theory of fatigue crack growth based on the total plastic energy

\footnotetext{
* Corresponding author.

E-mail addresses: nicolas.ranc@paris.ensam.fr (N. Ranc), thierry.palin-luc@bordeaux.ensam.fr (T. Palin-Luc), pcparis30@gmail.com (P.C. Paris).

URL: http://pimm.paris.ensam.fr/en/user/9 (N. Ranc).
} 


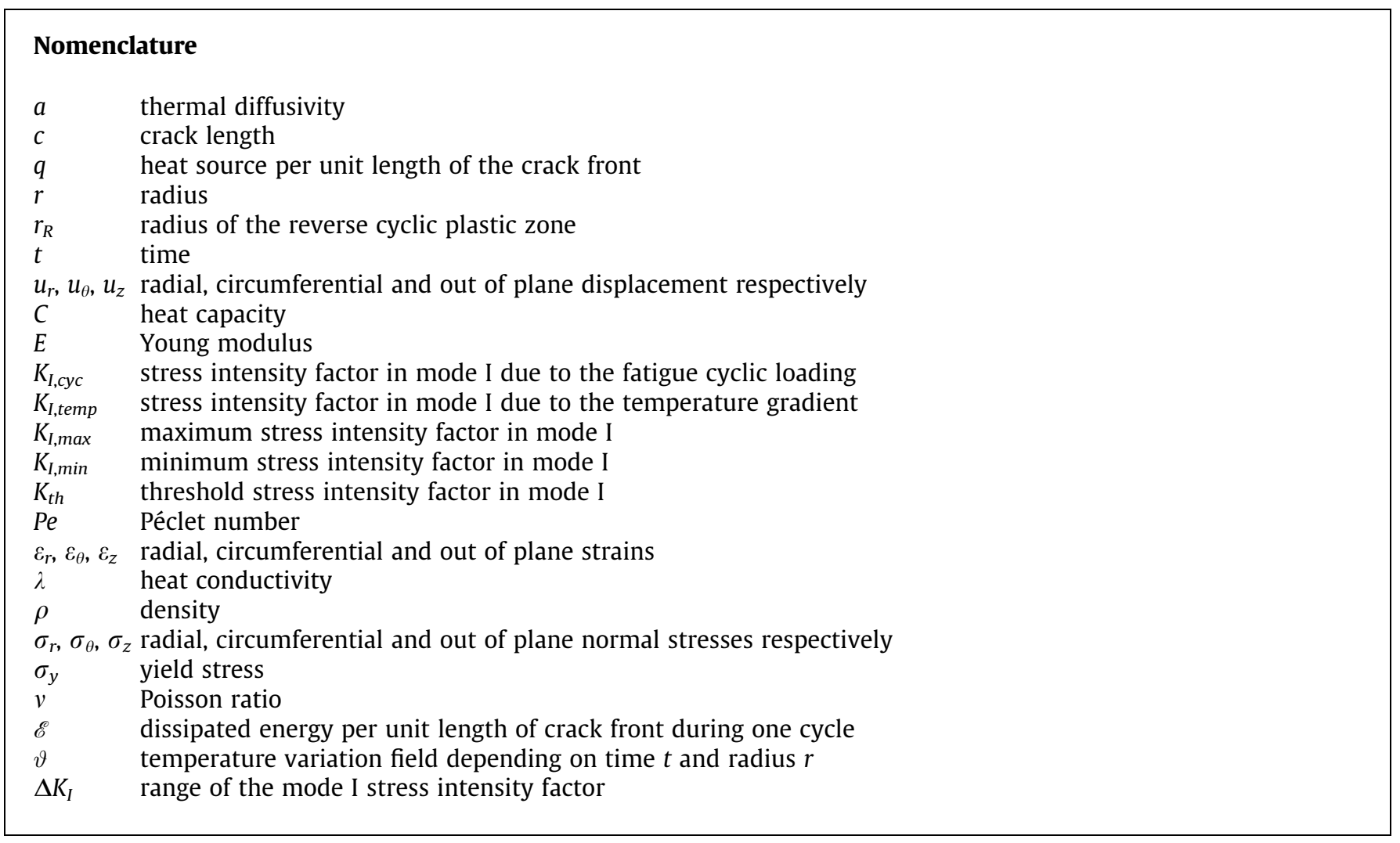

dissipation, Klingbeil [22] used in 2003 a finite element method to calculate the plastic dissipation per cycle ahead a crack in the particular case of a titanium alloy. But in this work no temperature estimation is carried out. Recently, Ranc et al. [23] used temperature field measurement on the surface of a specimen with an internal crack in order to study the crack propagation in the very high cycle fatigue domain and also quantify the dissipated energy of a circular crack. Except for the papers of Klingbeil and Ranc et al. no quantitative estimations of the dissipated energy associated with a fatigue crack are found in the literature. Furthermore, the study of the effect of the temperature field due to dissipation on the stress intensity factor has been ignored. The objective of this work is also to quantify this effect. However, there are two significant problems in order to estimate these thermal stresses: the first is the quantification of the heat source associated with the plasticity near the crack tip and the second is to make a good estimation of the boundary conditions of the thermal problem like convection from the surface of the cracked structure.

The proposed paper is focused on the theoretical problem of an infinite plate with a semi-infinite through crack loaded in fatigue in mode I. In the associated thermal problem, the thermal losses due to convection and radiation are neglected. After studying the temperature field associated with a slow moving fatigue crack in Section 2, the stress field due to this temperature field is calculated in Section 3 both analytically and numerically in both cases of plane stress and plane strain. This allows the calculation of the effect of the thermal stresses on the stress intensity factor (Section 4). It is shown that the crack tip is under compressive thermal stresses which participates in the crack closure effect. Finally, the consequences of the calculation on both the range, the ratio and the maximum and the minimum values of the stress intensity factor are discussed. Some recommendations for further theoretical and experimental investigations are proposed at the end of Section 4 and in conclusion.

\section{The temperature field associated with fatigue crack propagation}

During fatigue crack growth under cyclic loading, the cyclic plastic strains at each cycle are confined within the reverse cyclic plastic zone. A part of the plastic strain energy is dissipated in heat and generates a temperature variation. Generally, the size of this reverse cyclic plastic zone is very small. In order to determine the temperature field, it is possible to consider the thermal problem associated with the fatigue crack propagation as a line heat source centered in the reverse cyclic plastic zone along the crack tip in an infinitely thick body. Therefore, in this study this case will be compared with the case of a uniform heat source within a cylinder with a radius equal to the radius of the reverse cyclic plastic zone. The dissipated power per unit length of crack front is supposed to be proportional to the surface area of the reverse cyclic plastic zone and the loading frequency $f[23]$ :

$$
q=f \mathscr{E}=f \eta r_{R}^{2}
$$

with $\mathscr{E}$ the dissipated energy per unit length of crack front during one cycle, $r_{R}$ the radius of the reverse cyclic plastic zone and $\eta$ a material dependent proportionality factor. 
In the plane stress and plane strain cases, the reverse cyclic plastic zone radius are respectively

$$
r_{R}=\frac{\Delta K_{I}^{2}}{8 \pi \sigma_{y}^{2}} \text { and } r_{R}=\frac{\Delta K_{I}^{2}}{24 \pi \sigma_{y}^{2}},
$$

where $\Delta K_{I}$ is the range of variation of the mode I stress intensity factor and $\sigma_{y}$ is the cyclic yield stress of the material. For instance if we choose the following typical values $\sigma_{y}=500 \mathrm{MPa}$ and $\Delta K_{I}=5 \mathrm{MPa} \sqrt{\mathrm{m}}$, the value of the radius of the reverse cyclic plastic zone in plane stress is $4.0 \mu \mathrm{m}$ which remains small compared to the specimen size usually used in fracture mechanics tests. The dissipated power per unit length of crack front is therefore proportional to the variation of the stress intensity factor to the power four:

$$
q=q_{0} \Delta K^{4}
$$

These results have been already shown analytically [23] and numerically [22].

A constant heat source will be considered in this paper in such case an analytical solution for our problem exists. Furthermore, note that in general the fatigue crack velocity is small, especially when the stress intensity range $\Delta K$ is close to the threshold value $\Delta K_{t h}$. Since $q$ is proportional to $\Delta K^{4}$, for a slow moving crack, $\Delta K$ and also the heat source $q$ can be supposed constant. Moreover, in such case the heat source associated with the fatigue crack propagation can also be considered to be motionless. This assumption can be justified by the calculation of the Péclet number, noted $P e$, which compares the characteristic time of thermal diffusion with the characteristic time associated to the heat source velocity (i.e. the velocity of the reverse cyclic plastic zone at the crack tip). In this case the Péclet number is expressed by

$$
P e=\frac{L v}{a}
$$

where $L$ is the characteristic length of crack propagation, $v$ the crack velocity and $a$ the thermal diffusivity. For a crack length of around $1 \mathrm{~mm}$, a crack velocity of $0.1 \mathrm{~mm} \mathrm{~s}^{-1}$ and a thermal diffusivity of $1.5 \times 10^{-5} \mathrm{~m}^{2} \mathrm{~s}^{-1}$ (typical value for steel) it is possible to calculate a Péclet number of $6 \times 10^{-3}$. This value remains small compared to unity and therefore the heat source can also be considered as motionless.

Within all these assumptions, the thermal problem is axisymetric and if the line heat source is along the $z$ axis which is the normal direction to the surface of the plate (Fig. 1), the associated heat transfer equation is

$$
\rho C \frac{\partial T}{\partial t}=q \delta(0)+\lambda \frac{\partial^{2} T}{\partial r^{2}}
$$

with $\rho$ the density of the material, $C$ its heat capacity, $\lambda$ its heat conductivity and $\delta(r)$ the Dirac function.

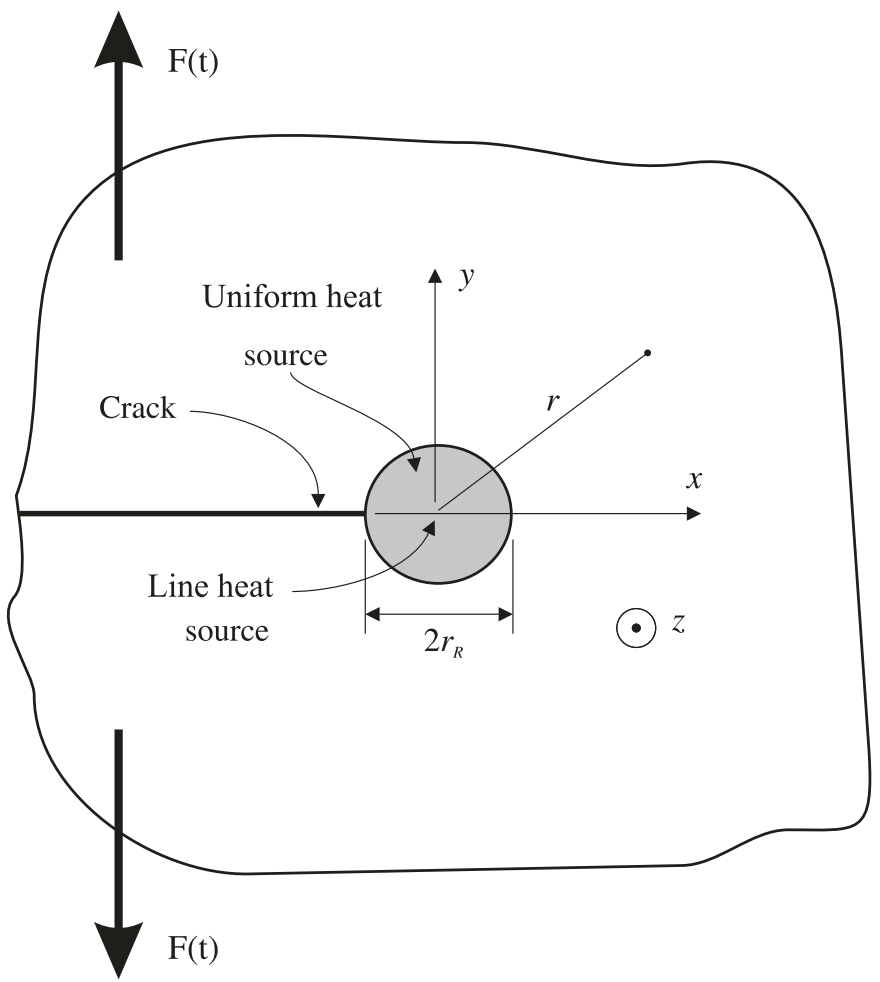

Fig. 1. Schematic of the thermomecanical problem of a semi-infinite crack in an infinite plate under cyclic tension (mode I) caused by a remotely mechanical loading $F(t)$ 


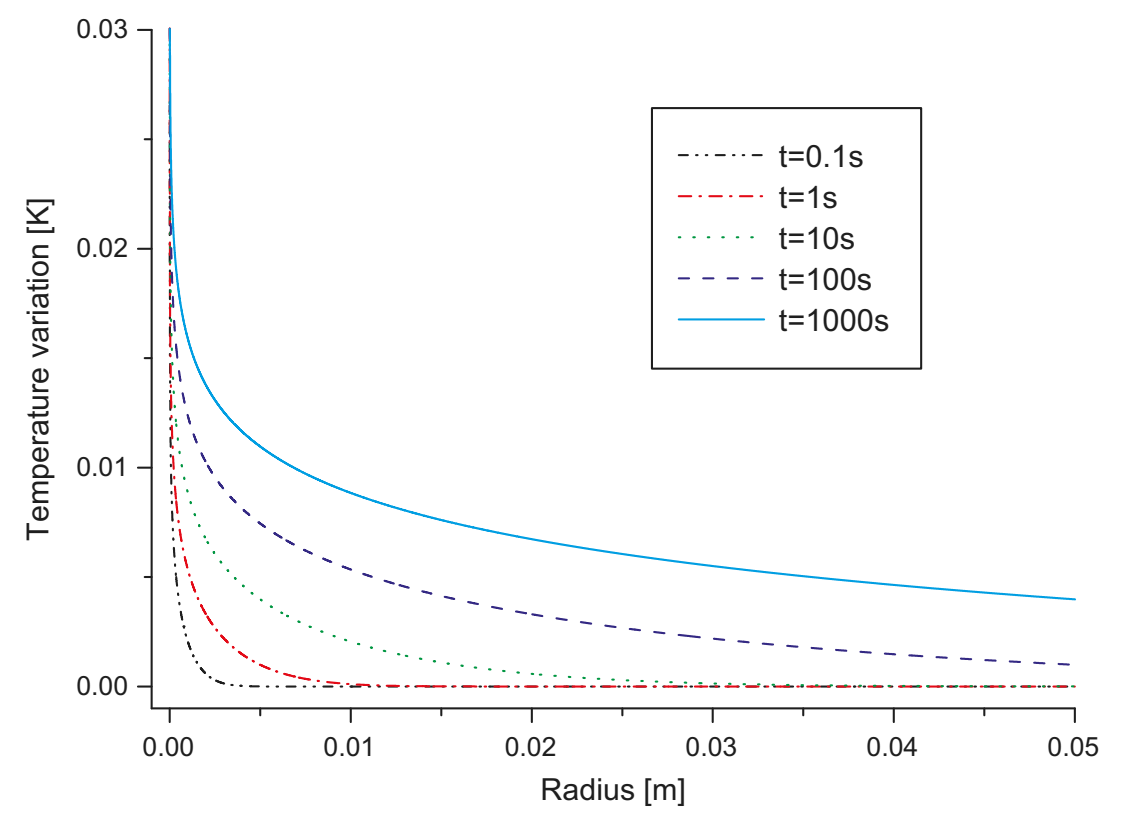

Fig. 2. The temperature variation field near the crack tip for $q=1 \mathrm{~W} \mathrm{~m}^{-1}$.

At time $t=0$, we suppose an homogeneous temperature $T_{0}$ of the plate. Between time $t=0$ and time $t$, the temperature variation field $\vartheta(r, t)=T(r, t)-T_{0}$ can be expressed by [24]:

$$
\vartheta(r, t)=\frac{1}{4 \pi \lambda} \int_{0}^{t} q \mathrm{e}^{-\frac{r^{2}}{4 a\left(t-t^{\prime}\right)}} \frac{\mathrm{d} t^{\prime}}{t-t^{\prime}},
$$

with $a=\frac{\lambda}{\rho C}$ the heat diffusivity. After the variable change $u=\frac{r^{2}}{4 a\left(t-t^{\prime}\right)}$, this integral becomes:

$$
\vartheta(r, t)=\frac{q}{4 \pi \lambda} \int_{\frac{r^{2}}{4 a t}}^{\infty} \frac{\mathrm{e}^{-u}}{u} \mathrm{~d} u=\frac{-q}{4 \pi \lambda} \mathrm{Ei}\left(-\frac{r^{2}}{4 a t}\right)
$$

with $-\operatorname{Ei}(-x)=\int_{x}^{\infty} \frac{\mathrm{e}^{-u}}{u} \mathrm{~d} u$ the integral exponential function.

Fig. 2 illustrates the evolution of the temperature variation field for different times according to the radius $r$ from the line heat source. For this calculation, standard thermal and physical properties for steel are used. The density, the heat capacity and the thermal conductivity are taken to be respectively $\rho=7800 \mathrm{~kg} \mathrm{~m}^{-3}, C=460 \mathrm{JK}^{-1} \mathrm{~kg}^{-1}$ and $\lambda=52 \mathrm{~W} \mathrm{~m} \mathrm{~K}^{-1}$. The dissipated power per unit length of crack front is chosen equal to the unit $\left(q=1 \mathrm{~W} \mathrm{~m}^{-1}\right)$. The curve on Fig. 2 shows that the temperature increases abruptly when the radius tends to zero. The temperature is proportional to the dissipated power (see Eq. (7)).

In the case of the uniform heat source in a cylinder with a radius equal to the radius of the reverse cyclic plastic zone (Fig. 1), the solution of the thermal problem can be found numerically with a one dimensional finite element method. In this numerical study, the infinite body is also modeled by a cylinder with an infinite thickness and a large radius of $1 \mathrm{~m}$. The boundary condition on the surface of this cylinder is adiabatic. In the finite element analysis done in our study, the size of the elements in and near the reverse cyclic plastic zone are taken equal to $0.3 \mu \mathrm{m}$. With this mesh, the effect of the element size on the value of temperature outside the reverse cyclic plastic zone remains negligible. Fig. 3 shows the comparison of the temperature variation field obtained with the line heat source and the uniform heat source hypothesis for time $t=10 \mathrm{~s}$. Outside of the reverse cyclic plastic zone (radius greater than $4 \mu \mathrm{m}$ ) the temperatures computed for these two assumptions are very close: for $r=4 \mu \mathrm{m}$ the relative difference is around $0.03 \%$. Therefore inside the reverse cyclic plastic zone the temperature can be very differently distributed, but this is not the aim of this paper. This study is focused on the effect of the temperature gradient on the stress state outside this plastic zone in order to calculate its consequence on the stress intensity factor.

\section{The stress field associated with the temperature field near the crack tip}

\subsection{The thermo-mechanical problem}

The temperature field associated with the heat source in the reverse cyclic plastic zone generates a temperature gradient varying with time outside this plastic zone and consequently thermal stresses due to the thermal expansion of the material. 


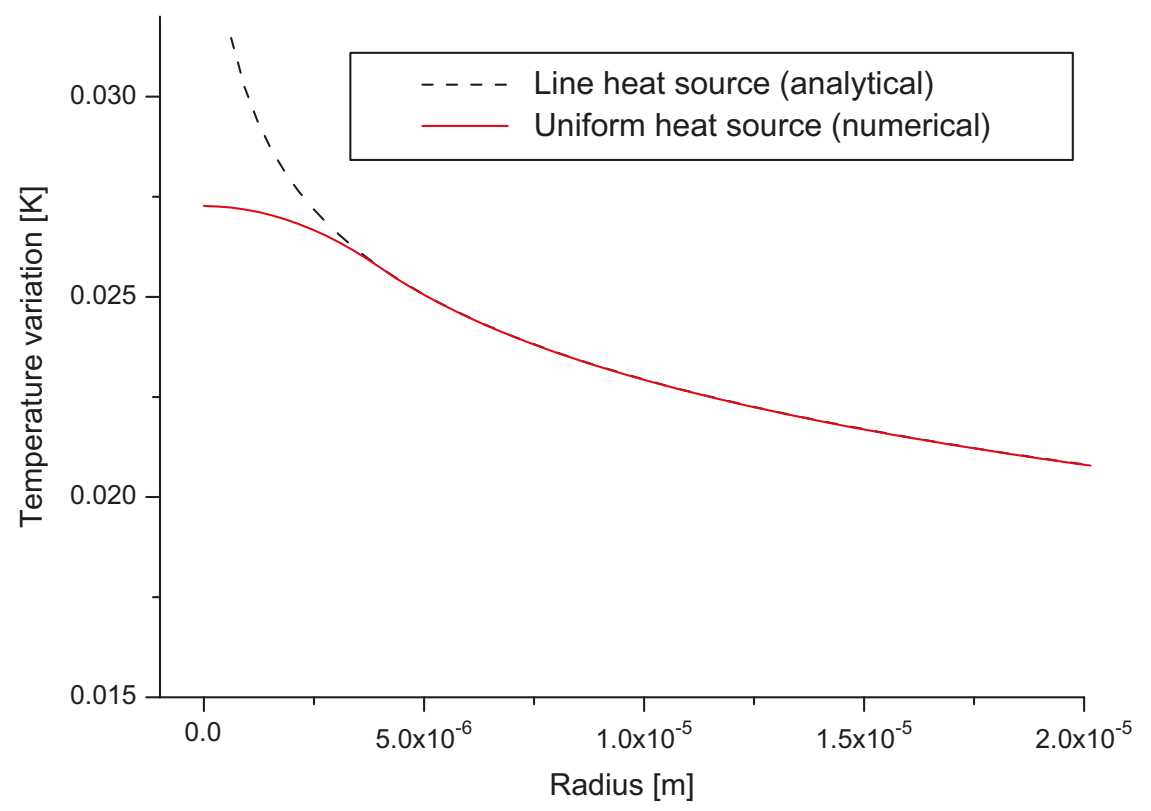

Fig. 3. Comparison of the temperature variation field for time $t=10 \mathrm{~s}$ in the case of a line heat source (analytic solution) and for a uniform radius heat source (numerical solution) both equal to $1 \mathrm{~W} \mathrm{~m}^{-1}$.

In order to estimate these thermal stresses the thermo-mechanical problem with the temperature field previously calculated needs to be solved. This thermo-mechanical problem is supposed to be bi-dimensional because the temperature field is axisymetric. Indeed, we consider the theoretical problem of an infinite plate with a semi-infinite through crack under mode I cyclic loading (Fig. 1). The cases of the plane stress and plane strain will be both considered. The material is assumed to be homogeneous and isotropic with an elastic plastic behavior and plastic strain occurs only in the reverse cyclic plastic zone (cylinder domain with a radius $r_{R}$ ).

In the both cases of plane stress and plane strain, there is unrestricted plastic flow through the thickness direction in the cracked specimen. With alternating plasticity in the reverse cyclic plastic zone the mean stress will tend toward to zero. Also in the thermo-mechanical problem, only the elastic domain is considered and the boundary condition in the reverse cyclic plastic zone radius is that the radial stress is equal to zero.

Further, outside of the reverse cyclic plastic zone since the constitutive behavior of the material is supposed to be elastic, it is expected in first approximation that the basic equations of thermo-elasticity will govern. The equilibrium equation is:

$$
r \frac{\partial \sigma_{r}}{\partial r}+\sigma_{r}-\sigma_{\theta}=0
$$

For which $\sigma_{r}$ is the radial normal stress and $\sigma_{\theta}$ is the circumferential normal stress.

The isotropic elastic stress strain law gives:

$$
\begin{aligned}
\varepsilon_{r} & =\frac{\partial u_{r}}{\partial r}=\frac{\sigma_{r}}{E}-v\left(\frac{\sigma_{\theta}+\sigma_{z}}{E}\right)+\alpha \vartheta(r, t), \\
\varepsilon_{\theta} & =\frac{1}{r} \frac{\partial u_{\theta}}{\partial \theta}+\frac{u_{r}}{r}=\frac{\sigma_{\theta}}{E}-v\left(\frac{\sigma_{r}+\sigma_{z}}{E}\right)+\alpha \vartheta(r, t), \\
\varepsilon_{z} & =\frac{\partial u_{z}}{\partial z}=\frac{\sigma_{z}}{E}-v\left(\frac{\sigma_{r}+\sigma_{\theta}}{E}\right)+\alpha \vartheta(r, t),
\end{aligned}
$$

where $E$ is the modulus of elasticity, $v$ the Poisson ratio and $\alpha$ is the linear coefficient of thermal expansion.

Two particular stress strain cases are considered for the elastic region: (i) plane stress where the normal stress $\left(\sigma_{z}\right)$ is equal to zero and (ii) plane strain where the strain $\left(\varepsilon_{z}\right)$ is equal to zero. In both cases the material behavior outside the reverse cyclic plastic zone is modeled by an isotropic thermo-elastic stress strain law. This set of equations is reduced to the same form, for example for plane stress they are reduced to the first two with $\sigma_{z}$ set equal to zero. For plane strain upon solving the last stress-strain equation for $\sigma_{z}$ and substituting it into the first two the same form is found with altered elastic and thermal constants. The plane stress form will be adopted here for simplicity and the plane strain alteration will only be noted in some final results. The plane stress case gives:

$$
\begin{aligned}
& \frac{\partial u_{r}}{\partial r}=\frac{\sigma_{r}}{E}-v \frac{\sigma_{\theta}}{E}+\alpha \vartheta(r, t), \\
& \frac{u_{r}}{r}=\frac{\sigma_{\theta}}{E}-v \frac{\sigma_{r}}{E}+\alpha \vartheta(r, t) .
\end{aligned}
$$


From the second of these, multiplying by $r$ and differentiating, results in

$$
\frac{\partial u_{r}}{\partial r}=\frac{\partial}{\partial r}\left[r\left(\frac{\sigma_{\theta}}{E}-v \frac{\sigma_{r}}{E}+\alpha \vartheta(r, t)\right)\right]
$$

Equating this to the first equation of the two above and rearranging, as well as introducing the equilibrium equation to eliminate $\sigma_{\theta}$, gives:

$$
r \frac{\partial^{2} \sigma_{r}}{\partial r^{2}}+3 \frac{\partial \sigma_{r}}{\partial r}=-\alpha^{\prime} E^{\prime} \frac{\partial \vartheta}{\partial r}
$$

where $E^{\prime}=E$ and $\alpha^{\prime}=\alpha$ for plane stress, whereas $E^{\prime}=\frac{E}{1-v^{2}}$ and $\alpha^{\prime}=\alpha(1+v)$ for plane strain. From Eq. (7), we find

$$
\frac{\partial \vartheta(r, t)}{\partial r}=\frac{-q \mathrm{e}^{-\frac{r^{2}}{4 a t}}}{2 \pi \lambda r}
$$

The equilibrium equation of the thermo-mechanical problem is then

$$
r \frac{\partial^{2} \sigma_{r}}{\partial r^{2}}+3 \frac{\partial \sigma_{r}}{\partial r}=\frac{q \alpha^{\prime} E^{\prime} \mathrm{e}^{-\frac{r^{2}}{4 a t}}}{2 \pi \lambda r}
$$

\subsection{An analytical solution of the thermo-mechanical problem}

The differential Eq. (12) can be solved by letting $\phi(r, t)=\frac{\partial \sigma_{r}}{\partial r}$ and viewing this equation with some rearranging as

$$
\frac{\partial \phi}{\partial r}+3 \frac{\phi}{r}=f(r, t)
$$

with $f(r, t)=+\frac{q \alpha^{\prime} E^{\prime}}{2 \pi \lambda r^{2}} \mathrm{e}^{-\frac{r^{2}}{4 a t}}$. Its solution is:

$$
\phi(r, t)=\frac{1}{r^{3}} \int r^{3} f(r, t) d r+\frac{C}{r^{3}},
$$

where $C$ is a constant. The expression of the $\phi$ function is then obtained after integration:

$$
\phi(r, t)=\frac{\partial \sigma_{r}(r, t)}{\partial r}=\frac{-\alpha^{\prime} E^{\prime} a q}{\pi \lambda}\left(\frac{t \mathrm{e}^{-\frac{r^{2}}{4 a t}}}{r^{3}}\right)+\frac{C}{r^{3}}
$$

The integration of this function allows one to obtain the radial stress:

$$
\sigma_{r}(r, t)=\frac{\alpha^{\prime} E^{\prime} a q}{\pi \lambda}\left(\frac{t}{2 r^{2}} \mathrm{e}^{\frac{-r^{2}}{4 a t}}+\frac{1}{8 a} \operatorname{Ei}\left(\frac{r^{2}}{4 a t}\right)\right)+\frac{F}{r^{2}}+G
$$

with $F$ and $G$ two integration constants. Eq. (8) allows one to find the circumferential stress:

$$
\sigma_{\theta}(r, t)=-\frac{\alpha^{\prime} E^{\prime} a q}{\pi \lambda}\left(\frac{1}{2} \frac{t e^{-\frac{r^{2}}{4 a t}}}{r^{2}}-\frac{1}{8 a} \mathrm{Ei}\left[\frac{-r^{2}}{4 a t}\right]\right)-\frac{F}{r^{2}}+G
$$

It is possible now to use the boundary conditions in order to express the two constants $F$ and $G$. The first mechanical boundary condition is, when $t>0$,

$$
\lim _{r \rightarrow+\infty} \sigma_{r}(r, t)=0
$$

because there is no thermal stress when $r$ tend to infinity. This condition implies $G=0$. The second mechanical boundary condition in $r_{R}$ is:

$$
\sigma_{r}\left(r_{R}, t\right)=0 \text { for } t>0
$$

because with alternating plasticity in the reverse cyclic plastic zone, the mean stress tends to zero. With Eq. (18), this condition allows one to express the constant, $F$, as follows, which is in fact a function depending on time to respect the boundary conditions whatever the time $t$.

$$
F=\frac{\alpha^{\prime} E^{\prime} a q r_{P}}{\pi \lambda}\left(-\frac{t}{2} \frac{e^{-\frac{r_{R}^{2}}{4 a t}}}{r_{R}}-\frac{r_{R}}{8 a} \operatorname{Ei}\left(\frac{-r_{R}^{2}}{4 a t}\right)\right)
$$

Then, the radial normal stress is

$$
\sigma_{r}(r, t)=\frac{\alpha^{\prime} E^{\prime} a q}{\pi \lambda r^{2}}\left[\frac{t}{2}\left(e^{\frac{r^{2}}{a a t}}-e^{\frac{-r_{R}^{2}}{4 a t}}\right)+\frac{1}{8 a}\left(r^{2} \operatorname{Ei}\left(\frac{-r^{2}}{4 a t}\right)-r_{R}^{2} \operatorname{Ei}\left(\frac{-r_{R}^{2}}{4 a t}\right)\right)\right],
$$


and the circumferential normal stress, from Eq. (8) is:

$$
\sigma_{\theta}(r, t)=\frac{-\alpha^{\prime} E^{\prime} q}{8 \pi \lambda r^{2}}\left\{4 a t\left(e^{-\frac{r^{2}}{4 a t}}-e^{-\frac{r_{R}^{2}}{4 a t}}\right)+\left[-r_{R}^{2} \operatorname{Ei}\left(\frac{-r_{R}^{2}}{4 a t}\right)-r^{2} \operatorname{Ei}\left(\frac{-r^{2}}{4 a t}\right)\right]\right\} .
$$

These radial and circumferential normal stresses are then calculated with a Young modulus $E$ and a Poisson ratio $v$ which are respectively equal to $210 \mathrm{GPa}$ and 0.29 . The thermal expansion of the material is chosen equal to the typical value $\alpha=1.2 \times 10^{-5} \mathrm{~K}^{-1}$ and the line heat source is taken equal to the unity $\left(q=1 \mathrm{~W} \mathrm{~m}{ }^{-1}\right)$. The Fig. 4 a gives for $r_{R}=4 \mu \mathrm{m}$ the evolution of the radial stress as it varies with the radius for two times $t=1 \mathrm{~s}$ and $t=10 \mathrm{~s}$. Note that the radial stress is always negative because the material is under compression due to the thermal expansion of the material near the crack tip. The Fig. $4 \mathrm{~b}$ is an enlargement of the curve around the reverse cyclic plastic zone. This figure shows a minimum of the radial stress. After $1 \mathrm{~s}$ and $10 \mathrm{~s}$, the minimum radial stresses are respectively equal to $-2.2 \times 10^{-2} \mathrm{MPa}$ and $-1.9 \times 10^{-2} \mathrm{MPa}$ and the respective positions from the center of the reverse cyclic plastic zone $(r=0)$ are $17 \mu \mathrm{m}$ and $16 \mu \mathrm{m}$ for a unit line heat source.

The Fig. 5a shows the evolution of the circumferential stress along a radial axis for two different times. Near the reverse cyclic plastic zone $\left(r=r_{R}=4 \mu \mathrm{m}\right)$ the circumferential stress is negative (Fig. $5 \mathrm{a}$ ) because the temperature is high and through the circumferential direction, the material is under compression due to the thermal expansion and the constraint effect.
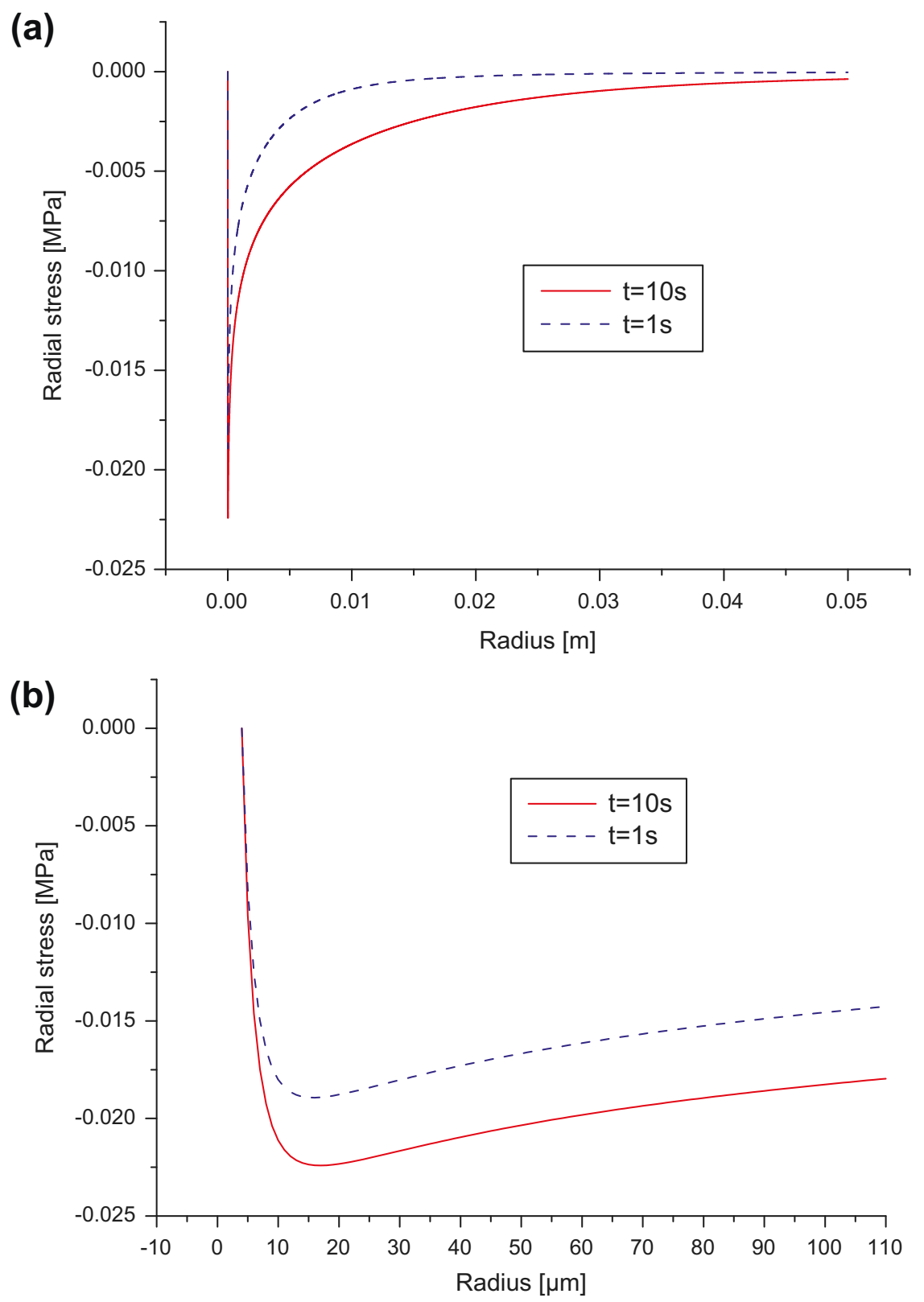

Fig. 4. The distribution of the radial normal stress for various times for a unit heat source $q=1 \mathrm{~W} \mathrm{~m}{ }^{-1}$ and $r_{R}=4 \mu \mathrm{m}$; (a) general view, (b) enlargement near the reverse cyclic plastic zone. 
Further from this zone, the temperature is lower and the circumferential stress becomes positive (tension) due to the confinement of the material near the crack tip (Fig. 5a). For times $t=1 \mathrm{~s}$ and $t=10 \mathrm{~s}$ the circumferential stress in the edge of the reverse cyclic plastic zone is respectively equal to $-0.056 \mathrm{MPa}$ and $-0.065 \mathrm{MPa}$ for a unit line heat source. It has to be pointed out that all the previous stress values are small because they are computed for a unit heat source $q$ (per unit length of crack front), but the stresses are proportional to $q$.

\subsection{A numerical solution of the thermo-mechanical problem}

The analytical solution presented in the last paragraph is for an infinite body with a semi-infinite through crack under tension (mode I). If we want to estimate the thermal stresses for another geometry like a finite specimen, it is easier to solve the thermo-mechanical problem with a finite element method. The objective of this paragraph is to compare the thermal stresses obtained with the finite element method with the analytical solution and also to check the difference between these two methods in the case of an infinite plate.

The previous thermo-mechanical problem is also numerically solved with the finite element method. In order to compare with the analytical solution the infinite cracked plate is modeled by a cylindrical plate with an external radius of $1 \mathrm{~m}$. On this
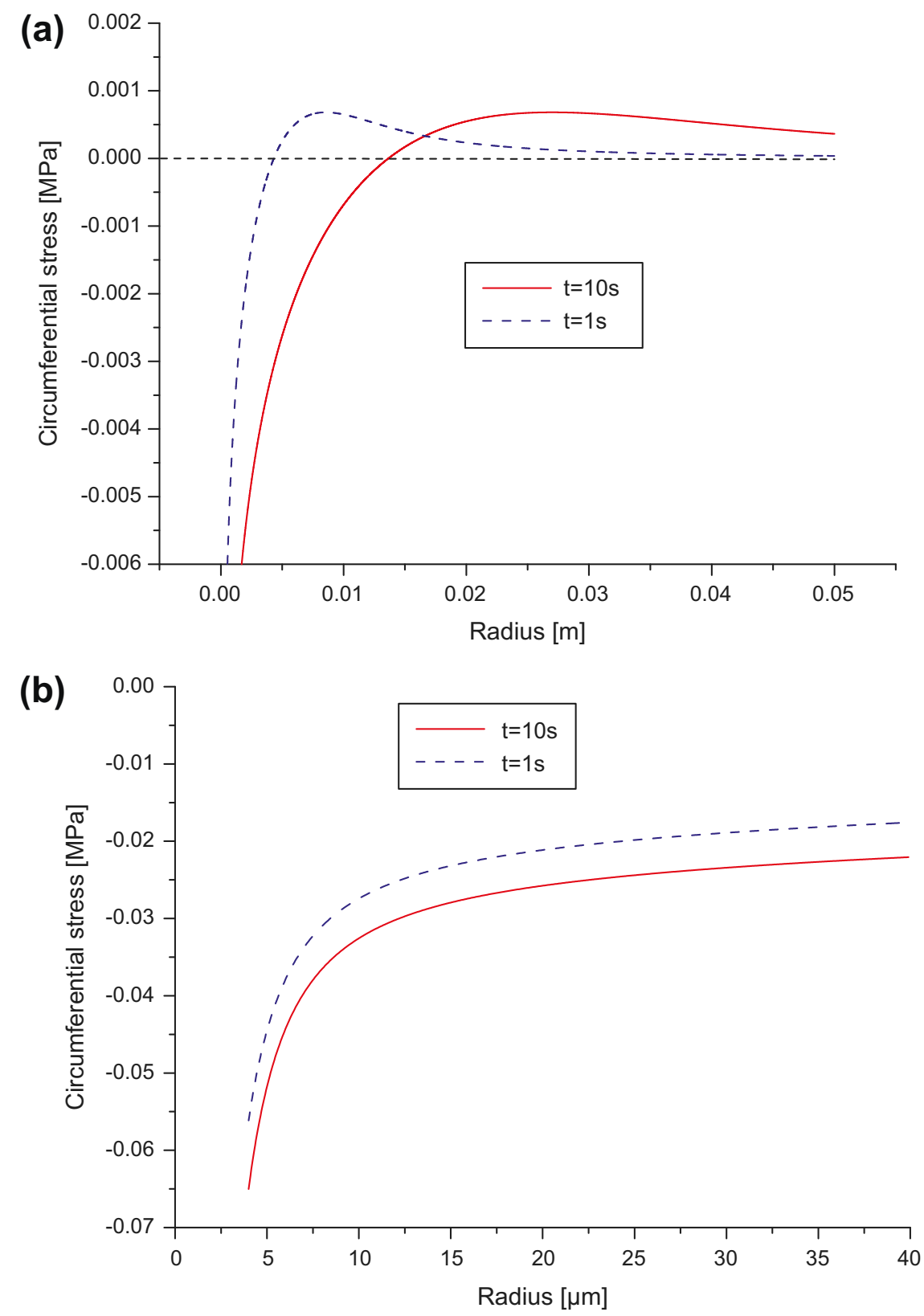

Fig. 5. The circumferential stress distribution at various times for a unit heat source $q=1 \mathrm{~W} \mathrm{~m}^{-1}$ and $r_{R}=4 \mu \mathrm{m}$; (a) general view, (b) enlargement near the reverse cyclic plastic zone. 


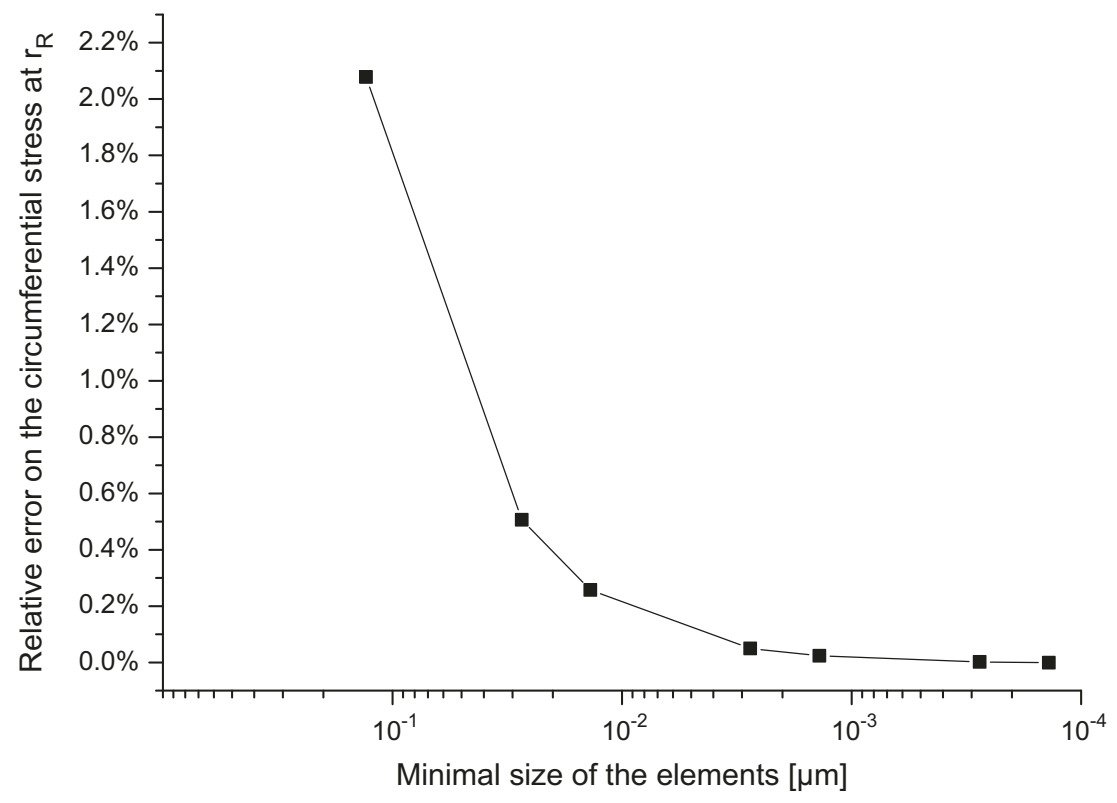

Fig. 6. Error on the circumferential stress $\sigma_{\theta}$ at $r=r_{R}$ versus the minimal element size for finite element simulation.

external surface, no stress is applied. The space is meshed with axisymetric elements. The size of the elements is very small near the reverse cyclic plastic zone and increases with the radius. Simulation for minimal elements size between $0.13 \mu \mathrm{m}$ and $1.4 \times 10^{-4} \mu \mathrm{m}$ were carried out. The stress evolutions along the radius with the numerical and analytical methods are the same. The Fig. 6 shows the relative difference between the circumferential stress at the radius, $r_{R}$, obtained with the numerical simulation and the analytical solution. This evolution is illustrated versus the minimal element size. Beyond element size of $2.8 \times 10^{-3} \mu \mathrm{m}$ the relative difference is smaller than $0.1 \%$.

\section{Estimation of the effect of the thermal stresses on the stress intensity factor under cyclic loading}

Now within the heterogeneous stress field due to the thermal stresses, if we consider the previous theoretical case of an infinite plate with a semi-infinite crack along a radial line from $r_{R}$ to $+\infty$, we can determine the associated stress intensity factor, $K_{I, t e m p}$, due to the temperature gradient from the wedge force (Green's function) solution ([25] page 87) as:

$$
K_{I, \text { temp }}(t)=\sqrt{\frac{2}{\pi}} \int_{r_{R}}^{\infty} \frac{\sigma_{\theta}(r, t)}{\sqrt{r-r_{R}}} \mathrm{~d} r .
$$

From Eqs. (24) and (25), the stress intensity factor due to thermal stresses is expressed by:

$$
K_{I, t e m p}(t)=\frac{-\alpha^{\prime} E^{\prime} q}{8 \pi \lambda} \sqrt{\frac{2}{\pi}}\left[\int_{r_{R}}^{\infty} \frac{4 a t}{r^{2} \sqrt{r-r_{R}}}\left(e^{-\frac{r^{2}}{4 a t}}-e^{-\frac{r_{R}^{2}}{4 a t}}\right) \mathrm{d} r+\int_{r_{R}}^{\infty} \frac{1}{r^{2} \sqrt{r-r_{R}}}\left(-r_{R}^{2} \operatorname{Ei}\left(\frac{-r_{R}^{2}}{4 a t}\right)-r^{2} \operatorname{Ei}\left(\frac{-r^{2}}{4 a t}\right)\right) \mathrm{d} r\right] .
$$

After integration (with the help of the Mathematica software) it becomes:

$$
\begin{aligned}
K_{I, \text { temp }}(t)= & \frac{\alpha^{\prime} E^{\prime} q}{80 \lambda} \sqrt{\frac{2}{\pi}}\left\{40 \sqrt{r_{R}}+\frac{20 a t\left(e^{-\frac{r_{R}^{2}}{4 a t}}-1\right)}{r_{R}^{3 / 2}}+5 \sqrt{r_{R}} \operatorname{Ei}\left(\frac{-r_{R}^{2}}{4 a t}\right)+\frac{10(a t)^{1 / 4}}{\Gamma\left(\frac{7}{4}\right)}\left(-3_{2} F_{2}\left[\left(\frac{-1}{4}, \frac{1}{4}\right),\left(\frac{1}{2}, \frac{3}{4}\right),\left(\frac{-r_{R}^{2}}{4 a t}\right)\right]\right)\right. \\
& +\frac{10(a t)^{1 / 4}}{\Gamma\left(\frac{7}{4}\right)}\left({ }_{2} F_{2}\left[\left(\frac{1}{4}, \frac{3}{4}\right),\left(\frac{1}{2}, \frac{7}{4}\right),\left(\frac{-r_{R}^{2}}{4 a t}\right)\right]\right)-\frac{8 r_{R}}{(a t)^{1 / 4} \Gamma\left(\frac{1}{4}\right)}\left(5_{2} F_{2}\left[\left(\frac{1}{4}, \frac{3}{4}\right),\left(\frac{5}{4}, \frac{3}{2}\right),\left(\frac{-r_{R}^{2}}{4 a t}\right)\right]\right) \\
& \left.-\frac{8 r_{R}}{(a t)^{1 / 4} \Gamma\left(\frac{1}{4}\right)}\left({ }_{2} F_{2}\left[\left(\frac{3}{4}, \frac{5}{4}\right),\left(\frac{3}{2}, \frac{9}{4}\right),\left(\frac{-r_{R}^{2}}{4 a t}\right)\right]\right)\right\},
\end{aligned}
$$

with the hypergeometric function

$$
{ }_{p} F_{q}\left(\left\{a_{1}, \ldots, a_{p}\right\} ;\left\{b_{1}, \ldots, b_{q}\right\} ; z\right)=\sum_{k=0}^{+\infty} \frac{\left(a_{1}\right)_{k} \ldots\left(a_{p}\right)_{k}}{\left(b_{1}\right)_{k} \ldots\left(b_{q}\right)_{k}} \frac{z^{k}}{k !},
$$

where $(a)_{k}=\frac{\Gamma(a+k)}{\Gamma(a)}=a(a+1)(a+2) \ldots(a+k-1)$ is the Pochhammer symbol and $\Gamma(x)=\int_{0}^{+\infty} u^{x-1} e^{-x} d u$ the Euler Gamma function. For instance in our case ${ }_{2} F_{2}\left(\left\{a_{1}, a_{2}\right\} ;\left\{b_{1}, b_{2}\right\} ; z\right)=\sum_{k=0}^{+\infty}\left(\frac{\left.\left(a_{1}\right)_{k}\left(a_{2}\right)_{k}\right)_{k}\left(b_{2}\right)_{k}}{k^{k}} \cdot{ }^{k}\right.$. 
The evolution of $K_{I, t e m p}$ (the thermal correction on $K_{I}$ ) versus time is presented in Fig. 7 for a unit line heat source $\left(q=1 \mathrm{~W} \mathrm{~m}{ }^{-1}\right.$ ) and the following typical material characteristics: $\rho=7800 \mathrm{~kg} \mathrm{~m}^{-3}, C=460 \mathrm{JK}^{-1} \mathrm{~kg}^{-1}, \lambda=52 \mathrm{~W} \mathrm{~m}^{-1} \mathrm{~K}^{-1}$, $\alpha=12.10^{-6} \mathrm{~K}^{-1}$ and $E=210 \mathrm{GPa}$. For instance, after times of $10 \mathrm{~s}$ and $100 \mathrm{~s}$ the thermal correction on the stress intensity factor is respectively $-1.2 \times 10^{-3} \mathrm{MPa} \sqrt{\mathrm{m}}$ and $-2.1 \times 10^{-3} \mathrm{MPa} \sqrt{\mathrm{m}}$ for a reverse cyclic plastic zone radius of $4 \mu \mathrm{m}$. These values are negative because the temperature field generates compressive circumferential normal stresses near the crack tip.

The correction on the stress intensity factor can also be evaluated from the finite element method solution of the circumferential normal stress. The integral of Eq. (25) is calculated with a trapezoidal numerical integration. The last term near the $r_{R}$ bound is calculated explicitly with a linear approximation of the circumferential stress. Fig. 8 gives the relative error on the correction of the stress intensity factor for various minimal element size. This result shows a very good convergence of the numerical method. For an element size smaller than $2.7 \times 10^{-2} \mu \mathrm{m}$ the relative error is under $0.1 \%$.

Fig. 7 shows the evolution versus time of the stress intensity factor $K_{I, t e m p}$ due to the temperature gradient for various values of the reverse cyclic plastic zone radius. This illustrates that $K_{I, t e m p}$ is not very sensitive to the size of the reverse cyclic plastic zone. This is due to the large dimensions of the plate considered in this paper. Indeed, an infinite plate is also

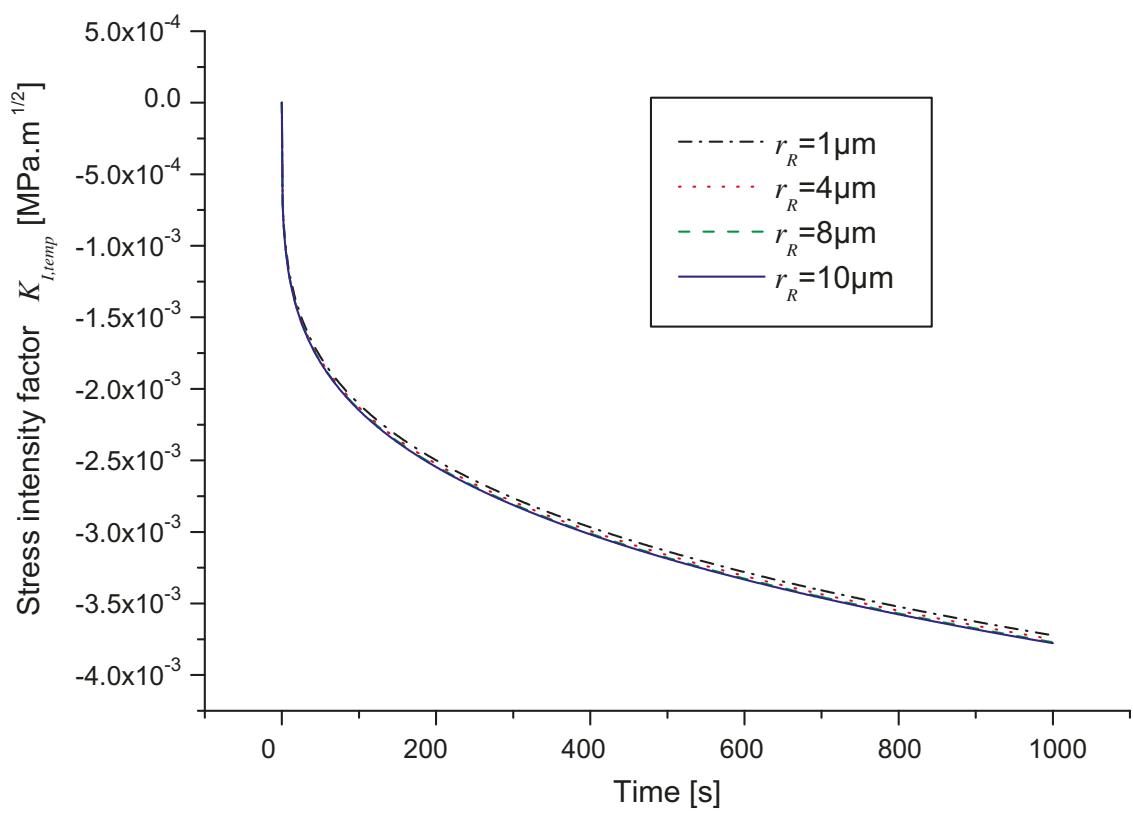

Fig. 7. The stress intensity factor $K_{I, t e m p}$ due to thermal stresses versus time for different radius of the reverse cyclic plastic zone.

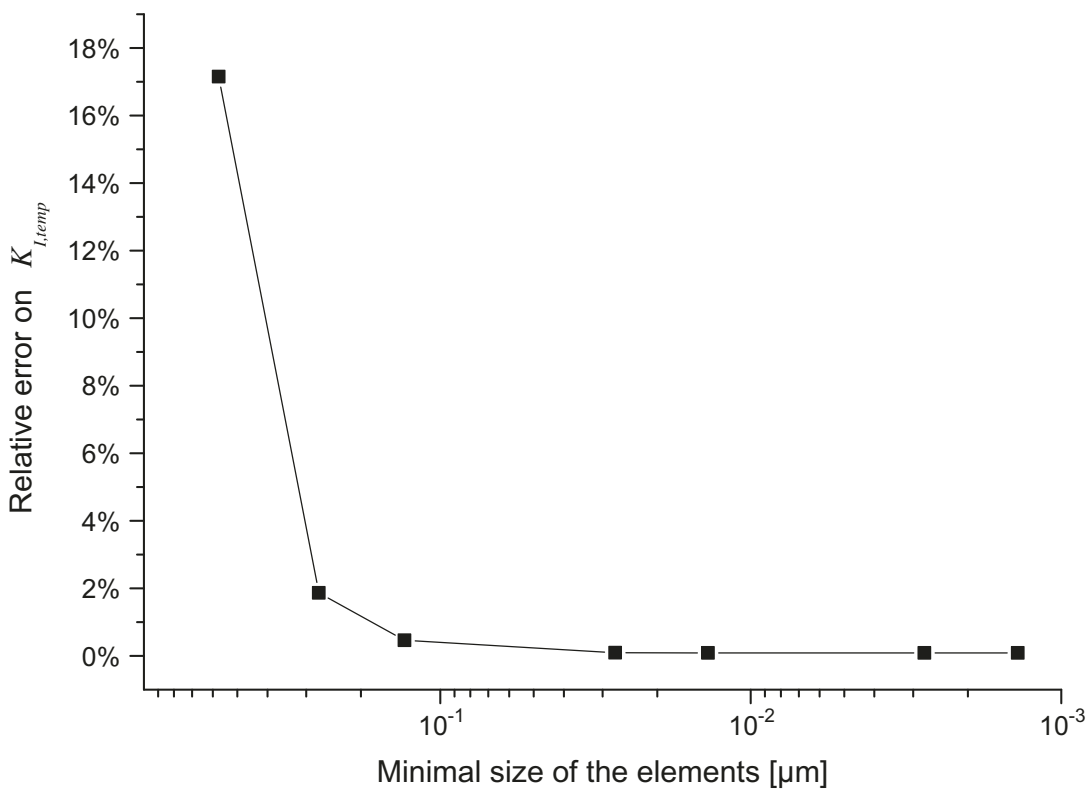

Fig. 8. Relative error on the stress intensity factor $K_{I, t e m p}$ due to thermal stresses versus to the minimal element size for the finite element analysis. 
considered for the analytic solution or a very large plate (compared to the reverse cyclic plastic zone) for the FEA. The thermal boundary conditions do not consider the heat exchange between the specimen and the environment that is the reason why no thermal equilibrium is reached even after a long time (Fig. 7). Further theoretical work in the analytic solution has to be done to take this phenomenon into account for being representative of small specimens (finite dimensions) for which thermal equilibrium is reached when a fatigue crack growth test is running during several hours in laboratory. This is the case of slow fatigue crack growth typically when the range of the stress intensity is close to the threshold.

The $K_{\text {I,temp }}$ determined by this equation would be a value superimposed on the usual stress intensity factor due to the fatigue cyclic loading noted $K_{I, c y c}$ in mode I.

$$
K_{I}(t)=K_{I, t e m p}(t)+K_{I, c y c}(t)
$$

As written before, due to the compressive thermal stresses around the crack tip it has been shown that the stress intensity factor during a fatigue loading has to be corrected by the factor $K_{I, t e m p}$.

$K_{I, \text { temp }}$ varies with time and can be considered as constant for long time. In the very beginning of loading, the value of $K_{I, t e m p}$ is small compared with $K_{I, c y c}$ and $\Delta K_{I}(t) \approx \Delta K_{I, c y c}$. There is also no significant effect of the temperature on the range of the stress intensity factor. For long time $(t \gg 0), K_{I, t e m p}$ can be considered as constant during a loading period. Consequently the temperature has no effect on $\Delta K_{I}$ but it has an effect on $K_{I, \text { max }}$ and $K_{I, \text { min }}$ :

$$
\begin{aligned}
& K_{I, \text { max }}=K_{I, \text { cyc } \max }+K_{I, \text { temp }}, \\
& K_{I, \text { min }}=K_{I, \text { cyc } \min }+K_{I, \text { temp }},
\end{aligned}
$$

where $K_{I, \min }$ and $K_{I, \max }$ are the minimum and the maximum value of $K_{I}(t)$ over a loading period. However, $K_{I, t e m p}$ can affect crack closure by changing the load ratio $R_{K}=\frac{K_{I, \min }}{K_{I, \max }}$. The ratio $R_{K}$ is affected by the temperature correction:

$$
R_{K}=\frac{K_{I, \min }}{K_{I, \max }}=\frac{K_{I, c y c \min }+K_{I, \text { temp }}}{K_{I, \text { cyc } \max }+K_{I, \text { temp }}} \neq \frac{K_{I, \text { cyc } \min }}{K_{I, \text { cyc } \max }}
$$

The evaluation of this correction needs a precise quantification of the heat source associated with the plastic dissipation and the thermal boundary conditions at the border of the plate. Experimental measurements of the temperature field, for instance by using pyrometry technique, need to be carried out in this way in a next study.

In this paper it has been shown that the effect of the heat source at the crack tip (within the reverse cyclic plastic zone) on the stress intensity factor is proportional to the line heat source $q$. The quantification of this is a key factor which is probably depending on the material behavior (plasticity, visco-plasticity if any). Another consequence of the thermal stresses is due to the fact that $q$ is proportional to $\Delta K^{4}$. When $\Delta K$ is changing significantly, for instance from the threshold $5 \mathrm{MPa} \sqrt{\mathrm{m}}$ up to $50 \mathrm{MPa} \sqrt{\mathrm{m}}$ (10 times more), the effect on the heat source is $10^{4}$ times! The effect on the correction due to thermal stresses is thus enormous. Furthermore, since the value of $q$ is also proportional to the loading frequency, a frequency effect on the crack growth may be also linked with the heat source. This opens interesting investigations for further studies.

We have to keep in mind that the problem solved here assumed that the heat source is motionless. This means that the proposed solution is physically correct for slow crack growth. This is the case when $\Delta K$ is close to the threshold value. For instance, with $\mathrm{d} c / \mathrm{d} N \sim 10^{-9} \mathrm{~m} /$ cycle at a loading frequency between $1 \mathrm{~Hz}$ up to $100 \mathrm{~Hz}$ the velocity of the crack tip (i.e. heat source velocity) is between $10^{-6} \mathrm{~mm} / \mathrm{s}$ and $10^{-4} \mathrm{~mm} / \mathrm{s}$. This means according to Eq. (4) that for a crack with a characteristic length between $1 \mathrm{~mm}$ and $10 \mathrm{~mm}$ that the Péclet number is small compare to the unity. In such a case, the motionless heat source hypothesis is correct and all the proposed results correct too. According to the authors, considering the effect of thermal stresses may be a very important point for studying the crack growth close to the threshold and for the physical phenomena including crack closure and frequency effect.

\section{Conclusion}

The temperature variation field outside the reverse cyclic plastic zone in an infinite plate with a semi-infinite crack under a remotely applied tensile force (mode I) has been calculated analytically. This temperature field also applies to a large central through crack, as an estimation near each crack tip. It shows that due to the temperature gradient outside the plastic zone, a local compressive stress field is created. This may participate in the crack closure phenomenon. The mode I stress intensity factor has then been calculated by taking into account this field. Both the effective range of the stress intensity factor (considering closure), the maximum and minimum values of $K_{I}$ and the stress intensity ratio $R_{K}=\frac{K_{I, \min }}{K_{I, \text { max }}}$ may be affected by the thermal stresses.

The proposed analytical solution for an infinite plate with a semi-infinite through crack under mode I fatigue loading where the heat source is modeled by a line heat source through the plate thickness is in very good agreement with the numerical solution (FEA). This means that the line heat source through the plate thickness is a good assumption. The proposed analytical solution shows that the correction on the stress intensity factor due to the heterogeneous temperature field around the crack tip is proportional to the heat source within the reversed cyclic plastic zone. Experimental investigation has to be carried out to quantify the heat source at the crack tip which is clearly a key factor in fracture mechanics. Further studies should be carried out in thermomechanics to take into account the temperature field effect on fracture mechanics considerations. 


\section{Acknowledgements}

The authors acknowledge Arts et Métiers ParisTech and Fondation Arts et Métiers for the financial support of Paul C. Paris' stay at LAMEFIP in 2009. The encouragement of Prof. Ivan Iordanoff, Director of LAMEFIP, is acknowledged with thanks. The effective mathematical assistance of Dr. Hiroshi Tada is also acknowledged.

\section{References}

[1] Paris PC. Fatigue-the fracture mechanics approach. Fatigue an interdisciplinary approach. Syracuse University Press; 1964.

[2] Rice JR. The mechanics of crack tip deformation and extension by fatigue, Fatigue crack propagation, ASTM, Special Technical Publication 415, Philadelphia; 1967. pp. 247-311.

[3] Elber W. Fatigue crack closure under cyclic tension. Engng Fract Mech 1970;2(1):37-45 [cited By (since 1996): 475].

[4] Farren WS, Taylor GI. The heat developed during plastic extension of metals. Proc Roy Soc A 1925;107:422-51.

[5] Taylor GI, Quinney H. The latent energy remaining in a metal after cold working. Proc Roy Soc A 1934;143:307-26.

[6] Rice JR, Levy N. Local heating by plastic deformation at a crack tip. Physics strength and plasticity. Cambridge, Mass.: M.I.T. Press; 1969.

[7] Li W, Deng X, Rosakis AJ. Determination of temperature field around a rapidly moving crack-tip in an elastic-plastic solid. Int J Heat Mass Transfer 1996;39(4):677-90 [cited By (since 1996): 3].

[8] Döll W. An experimental study of the heat generated in the plastic region of a running crack in different polymeric materials. Engng Fract Mech $1973 ; 5(2): 259-68$

[9] Wilson ML, Hawley RH, Duffy J. The effect of loading rate and temperature on fracture initiation in 1020 hot-rolled steel. Engng Fract Mech 1980;13(2):371-85 [cited By (since 1996): 7].

[10] Zehnder AT, Rosakis AJ. On the temperature distribution at the vicinity of dynamically propagating cracks in 4340 steel. J Mech Phys Solids $1991 ; 39(3): 385-415$.

[11] Guduru PR, Zehnder AT, Rosakis AJ, Ravichandran G. Dynamic full field measurements of crack tip temperatures. Engng Fract Mech 2001;68(14):1535-56 [cited By (since 1996): 23].

[12] Jha M, Narasimhan R. A finite element analysis of dynamic fracture initiation by ductile failure mechanisms in a 4340 steel. Int J Fract 1992;56(3):209-31 [cited By (since 1996): 6].

[13] Liaw PK, Wang H, Jiang L, Yang B, Huang JY, Kuo RC, et al. Thermographic detection of fatigue damage of pressure vessel steels at $1000 \mathrm{~Hz}$ and $20 \mathrm{~Hz}$. Scripta Mater 2000;42(4):389-95 [cited By (since 1996): 54].

[14] Yang B, Liaw PK, Wang H, Jiang L, Huang JY, Kuo RC, et al. Thermographic investigation of the fatigue behavior of reactor pressure vessel steels. Mater Sci Engng A 2001;314(1-2):131-9 [cited By (since 1996): 56].

[15] Fargione G, Geraci A, Rosa GL, Risitano A. Rapid determination of the fatigue curve by the thermographic method. Int J Fatigue 2002;24(1):11-9 [cited By (since 1996): 27].

[16] Bhalla KS, Zehnder AT, Han X. Thermomechanics of slow stable crack growth: closing the loop between experiments and computational modeling. Engng Fract Mech 2003;70(17):2439-58 [cited By (since 1996): 5].

[17] Boulanger T, Chrysochoos A, Mabru C, Galtier A. Calorimetric analysis of dissipative and thermoelastic effects associated with the fatigue behavior of steels. Int J Fatigue 2004;26(3):221-9 [cited By (since 1996): 36].

[18] Cura F, Curti G, Sesana R. A new iteration method for the thermographic determination of fatigue limit in steels. Int J Fatigue 2005;27(4):453-9 [cited By (since 1996): 26].

[19] Morabito AE, Chrysochoos A, Dattoma V, Galietti U. Analysis of heat sources accompanying the fatigue of 2024 t3 aluminium alloys. Int J Fatigue 2007;29(5):977-84 [cited By (since 1996): 9].

[20] Meneghetti G. Analysis of the fatigue strength of a stainless steel based on the energy dissipation. Int J Fatigue 2007;29(1):81-94 [cited By (since 1996): 19].

[21] Plekhov OA, Saintier N, Palin-Luc T, Uvarov SV, Naimark OB, analysis Theoretical. infrared and structural investigations of energy dissipation in metals under cyclic loading. Mater Sci Engng A 2007;462(1-2):367-9 [cited By (since 1996): 2].

[22] Klingbeil NW. A total dissipated energy theory of fatigue crack growth in ductile solids. Int J Fatigue 2003;25(2):117-28 [cited By (since 1996): 13].

[23] Ranc N, Wagner D, Paris PC. Study of thermal effects associated with crack propagation during very high cycle fatigue tests. Acta Mater 2008;56(15):4012-21 [cited By (since 1996): 4].

[24] Carslaw HS, Jaeger JC. Conduction of heat in solids. Oxford: Clarendon Press; 1947.

[25] Tada H, Paris PC, Irwin GR. The stress analysis of cracks handbook. A.S.M.E. Press; 2000. 